\title{
Effects of Environmental Manipulations and Treatment with Bupropion and Risperidone on Choice between Methamphetamine and Food in Rhesus Monkeys
}

\author{
Matthew L Banks*,I,2 and Bruce E Blough ${ }^{3}$ \\ 'Department of Pharmacology and Toxicology, Virginia Commonwealth University, Richmond, VA, USA; ${ }^{2}$ Institute for Drug and Alcohol Studies, \\ Virginia Commonwealth University, Richmond, VA, USA; ${ }^{3}$ Center for Drug Discovery, Research Triangle Institute, Research Triangle Park, NC, USA
}

Preclinical and human laboratory choice procedures have been invaluable in improving our knowledge of the neurobiological mechanisms of drug reinforcement and in the drug development process for candidate medications to treat drug addiction. However, little is known about the neuropharmacological mechanisms of methamphetamine vs food choice. The aims of this study were to develop a methamphetamine vs food choice procedure and determine treatment effects with two clinically relevant compounds: the monoamine uptake inhibitor bupropion and the dopamine antagonist risperidone. Rhesus monkeys $(n=6)$ responded under a concurrent schedule of food delivery ( I-g pellets, fixed-ratio (FR) 100 schedule) and intravenous methamphetamine injections (0-0.32 mg/ $/ \mathrm{kg} / \mathrm{inj}$ ection, FRIO schedule) during 7-day bupropion $(0.32-1.8 \mathrm{mg} / \mathrm{kg} / \mathrm{h})$ and risperidone $(0.001-0.0056 \mathrm{mg} / \mathrm{kg} / \mathrm{h})$ treatment periods. For comparison, effects of removing food pellets or methamphetamine injections and FR response requirement manipulations were also examined. Under saline treatment conditions, food was preferred over no methamphetamine or small unit methamphetamine doses (0.0 I-0.032 mg/ $/ \mathrm{kg} / \mathrm{injection})$. Larger methamphetamine doses resulted in greater methamphetamine preference and $0.32 \mathrm{mg} / \mathrm{kg} /$ injection methamphetamine maintained near exclusive preference. Removing food availability increased methamphetamine choice, whereas removing methamphetamine availability decreased methamphetamine choice. Methamphetamine choice was not significantly altered when the FR response requirements for food and drug were the same (FRI00:FRI00 or FRI 0:FRI0). Risperidone treatment increased methamphetamine choice, whereas bupropion treatment did not alter methamphetamine choice up to doses that decreased rates of operant behavior. Overall, these negative results with bupropion and risperidone are concordant with previous human laboratory and clinical trials and support the potential validity of this preclinical methamphetamine vs food choice model.

Neuropsychopharmacology (20I5) 40, 2198-2206; doi:I0.I038/npp.20I5.63; published online 8 April 2015

\section{INTRODUCTION}

Methamphetamine addiction is an insidious and world public health issue for which no effective pharmacotherapies exist (Courtney and Ray, 2014). The United Nations Office on Drugs and Crime World Drug Report UNODC (2013) states 'the use of amphetamine-type stimulants remains widespread, and appears to be increasing in most regions'. Prevalence estimates of amphetamine-type stimulant use within the past year for persons aged $15-64$ are $0.7 \%$ of the global population (UNODC, 2013). Moreover, the number of past year methamphetamine initiates among persons aged $\geqslant 12$ years is 144000 for 2013, and this number has been relatively stable since 2009 (SAMHSA, 2014).

Both neurochemical and behavioral studies suggest there are differences between methamphetamine, amphetamine,

* Correspondence: Dr ML Banks, Department of Pharmacology and Toxicology, Virginia Commonwealth University, 410 N. 12th Street, PO Box 9806।3, Richmond, VA 23298, USA, Tel: + I 8048288466 , Fax: + 804828 21 17, E-mail: mbanks7@vcu.edu Received I 8 November 20।4; revised 3 March 2015; accepted 4 March 2015; accepted article preview online 6 March 2015 and cocaine beyond methamphetamine and amphetamine functioning as monoamine releasers and cocaine functioning as a monoamine uptake inhibitor. In vitro and ex vivo studies suggest methamphetamine was more potent than amphetamine to induce dopamine (DA) release (Goodwin et al, 2009). In nonhuman primate drug self-administration studies, methamphetamine functions as a more potent but equally efficacious reinforcer compared with cocaine (Fantegrossi et al, 2002; Lile et al, 2013). In contrast, amphetamine was less efficacious than both methamphetamine and cocaine (Lile et al, 2013). Human laboratory self-administration results also suggest a trend for methamphetamine to be a more efficacious reinforcer than amphetamine (Kirkpatrick et al, 2012). Overall, this literature body suggests two main findings. First, there are apparent pharmacological differences between methamphetamine, amphetamine, and cocaine that may impact drug reinforcement and processes related to drug addiction. Second, these pharmacological differences may also impact the development of pharmacotherapies for the treatment of drug addiction, and medication efficacy for amphetamine or cocaine addiction may or may not translate to methamphetamine addiction. 
Preclinical drug $v s$ food choice procedures have been utilized for almost 40 years to understand both the environmental (Wurster et al, 1977) and pharmacological determinants (Woolverton and Balster, 1981) of human drug-taking behaviors. In particular, there are three potential advantages for the use of choice procedures in the medication development process for drug addiction. First, human laboratory drug self-administration studies, in general (Comer et al, 2008; Haney and Spealman, 2008), and methamphetamine selfadministration studies, in particular (De La Garza et al, 2010; Hart et al, 2001; Stoops et al, 2013), almost exclusively use a concurrent schedule of reinforcement where subjects allocate their behavior between drug (methamphetamine) and a concurrently available alternative, nondrug reinforcer (money). The use of preclinical choice procedures may facilitate translation of animal-to-human results. Second, these choice procedures generate dependent measures of behavioral allocation in addition to dependent measures of behavioral rates. Concurrent assessment of these two dependent measures allow for dissociation of experimental manipulations that selectively alter the relative reinforcing effects (changes in behavioral allocation) of the self-administered drug from pharmacological treatments that impair motor or cognitive competence (changes in responses rates) (Banks and Negus, 2012; Griffiths et al, 1975). Finally, drug addiction can be conceptualized to as maladaptive behavior in an environment that includes other non-drug reinforcers (Heyman, 2009), and treatment of drug addiction should not only reduce drug-taking behavior but also promote a reallocation of behavior to non-drug reinforcers (Banks and Negus, 2012; Vocci, 2007). Preclinical choice procedures allow for an explicit, although simplified, model of this environmental 'choice' context.

Although there is a rich scientific literature of preclinical choice procedures, there are a paucity of published methamphetamine $v$ food choice studies (Caprioli et al, 2015; John et al, 2015a; Ping and Kruzich, 2008). There were two major aims of the present study. The first aim was to establish experimental conditions that would permit assessment of behavioral allocation between food and multiple intravenous (IV) methamphetamine doses within a single experimental session. The second aim was to determine 7-day treatment effects of two compounds, bupropion and risperidone, that have been examined in human laboratory and clinical trials as candidate pharmacotherapies for methamphetamine addiction. The monoamine uptake inhibitor bupropion was selected because bupropion (1) antagonizes methamphetamineinduced DA efflux in vitro (Simmler et al, 2013), (2) treatment attenuates methamphetamine reinforcement in preclinical methamphetamine self-administration studies (Reichel et al, 2008; Reichel et al, 2009; Schindler et al, 2011), (3) blunts methamphetamine subjective effects in human laboratory studies (Newton et al, 2006), and (4) has shown weak or no efficacy in double-blind placebo-controlled clinical trials (Elkashef et al, 2008; Heinzerling et al, 2014; Shoptaw et al, 2008). Risperidone was selected as a representative DA antagonist medication, because it is a nonselective DA D1and D2-family antagonist with high D2-family occupancy (Lako et al, 2013). Furthermore, risperidone has shown weak or no efficacy as a treatment for methamphetamine addiction in both human laboratory (Wachtel et al, 2002) and clinical trials (Meredith et al, 2009; Nejtek et al, 2008).

\section{MATERIALS AND METHODS}

\section{Animals}

Six experimentally naive, adult male rhesus monkeys (Macaca mulatta) were surgically implanted with a doublelumen catheter $(0.76 \mathrm{~mm}$ ID $\times 2.36 \mathrm{~mm}$ OD, STI Flow, Morrisville, NC) inserted into a femoral or jugular vein. Monkeys weighed between 8 and $11 \mathrm{~kg}$ and were maintained on a diet of fresh fruit and food biscuits (Lab Diet High Protein Monkey Biscuits no. 5045, PMI Nutrition, St Louis, $\mathrm{MO}$ ) provided in the afternoon after the operant behavioral session. Water was continuously available in the housing cage. A 12-h light-dark cycle was in effect (lights on from 0600 to 1800 hours). Animal research and maintenance were conducted according to the Guide for the Care and Use of Laboratory Animals (Eighth edition) as adopted and promulgated by the National Institutes of Health. Animal facilities were licensed by the United States Department of Agriculture and accredited by the Association for Assessment and Accreditation of Laboratory Animal Care. The Institutional Animal Care and Use Committee approved the research and environmental enrichment protocol. Moreover, monkeys had visual, auditory, and olfactory contact with other monkeys throughout the study. Operant procedures and foraging toys were provided for environmental manipulation and enrichment. Videos were also played daily in animal housing rooms to provide additional environmental enrichment.

\section{Apparatus}

The home chamber served as the experimental chamber. Briefly, each chamber was equipped with a custom operant panel, a pellet dispenser (Med Associates, Model ENV-203-1000, St Albans, VT), and two syringe pumps (Model PHM-108, Med Associates). One 'self-administration' pump delivered contingent methamphetamine or saline injections through one lumen of the catheter. The second 'treatment' pump delivered a 0.1- $\mathrm{ml}$ saline, bupropion, or risperidone infusion through the second lumen of the catheter at a programmed rate of every $20 \mathrm{~min}$ from 1200 hours each day until 1100 hours the next morning. The IV catheter was protected by a customized stainless steel tether and jacket system (Lomir Biomedical, Malone, NY) that permitted monkeys to move freely. Catheter patency was periodically evaluated by IV ketamine $(5 \mathrm{mg} / \mathrm{kg})$ administration through one lumen of the double-lumen catheter and after any environmental or pharmacological manipulation that produced a decrease in methamphetamine $v s$ food choice. The catheter was considered patent if IV ketamine administration produced a loss of muscle tone within $10 \mathrm{~s}$.

\section{Behavioral Procedure}

Initially, key pressing was shaped for food-maintained (1-g banana-flavored pellets, Test Diets, Richmond, IN) responding up to the terminal fixed-ratio (FR) FR100 schedule of reinforcement. After catheter implantation, methamphetamine-maintained $(0.1 \mathrm{mg} / \mathrm{kg} /$ injection $)$ responding was initially shaped up to the terminal FR10 schedule of reinforcement. Under the terminal choice procedure, monkeys responded under a concurrent schedule of food 
and IV methamphetamine $(0.01-0.32 \mathrm{mg} / \mathrm{kg} /$ injection) availability. Choice sessions were implemented daily from 0900 to 1100 hours and consisted of five 20 -min components, with a different unit methamphetamine dose available during each successive component $(0,0.01,0.032,0.1$, and $0.32 \mathrm{mg} / \mathrm{kg} /$ injection during components $1-5$, respectively). Components were separated by 5 -min timeout periods. Manipulating the injection volume controlled the methamphetamine dose $(0,0.03,0.1,0.3$, and $1.0 \mathrm{ml} /$ injection, respectively). During each component, the left, food-associated key was transilluminated red, and completion of the FR requirement (FR100) resulted in 1-g food pellet delivery. The right, methamphetamine-associated key was transilluminated green, and completion of the FR requirement (FR10) resulted in delivery of the IV unit methamphetamine dose available during that component. Stimulus lights for the methamphetamineassociated key were flashed on and off in 3-s cycles, and longer flashes were associated with higher methamphetamine doses. Monkeys could complete up to a total of 10 ratio requirements on both the food- and methamphetamineassociated keys. Responding on either key reset the ratio requirement on the other key. Completion of each ratio requirement initiated a 30-s timeout, during which all stimulus lights were turned off, and responding had no programmed consequences. Choice behavior was considered stable when the lowest unit methamphetamine dose maintaining $>80 \%$ methamphetamine $v s$ food choice varied by $\leqslant 0.5 \log$ units for 3 consecutive days. Experimental parameters (unit methamphetamine dose and dose order, alternative food reinforcer magnitude, and ratio requirement on food- and methamphetamine-associated keys) of the choice session used in this study were based on initial preliminary studies and parameters used to assess environmental and pharmacological mechanisms of cocaine $v s$ food and heroin vs food choice (Negus, 2003; Negus, 2006). Consequently, with the parameters used in this study, we predicted we would have sensitivity to detect both leftward and rightward shifts in the methamphetamine $v s$ food choice dose-effect function that might result from experimental manipulations.

Once methamphetamine $v s$ food choice was stable, test sessions were conducted to determine bupropion or risperidone treatment effects on methamphetamine $v s$ food choice. Bupropion $(0.32-1.8 \mathrm{mg} / \mathrm{kg} / \mathrm{h})$ or risperidone $(0.001-$ $0.0056 \mathrm{mg} / \mathrm{kg} / \mathrm{h}$ ) was administered IV instead of saline for 7 consecutive days via the 'treatment' pump, and the 3-day period of saline infusions before each test drug treatment was used as the baseline ' + saline'. At the conclusion of each 7-day treatment periods, saline infusions were reinstituted for at least 4 days and until methamphetamine $v$ f food choice had returned to pretreatment levels. Saline, bupropion, and risperidone doses were counterbalanced across subjects.

In a second set of experiments, availability of either methamphetamine or food was temporarily removed for 7 consecutive days to establish boundary conditions for comparison to test compound effects. Specifically, these conditions were studied to examine effects of the extreme case wherein reinforcing consequences associated with either methamphetamine or food choice was eliminated. To remove methamphetamine availability, the methamphetamine solution was replaced with saline in the 'self-administration' pump for 7 days so that all other stimuli, including IV injections, were the same under both conditions. To remove food availability, food pellets were removed from the pellet dispenser so that all other stimuli, including the sound of the pellet dispenser motor, were the same under both conditions. At the end of each 7-day test period, standard conditions of methamphetamine and food availability were reinstated until choice behavior recovered to baseline levels.

In a third set of experiments, the relative response requirements for food pellets and methamphetamine injections were manipulated to assess the degree to which methamphetamine $v s$ food preference was sensitive to response cost manipulations. Specifically, the FR requirement on the foodassociated key was held at FR100 and the FR value on the methamphetamine-associated key was increased to FR100, or the methamphetamine-associated key was held at FR10 and the FR value on the food-associated key was decreased to FR10. Each FR manipulation was, in effect, for 7 consecutive days and FR manipulations were counterbalanced between subjects. Baseline FR requirements (Food FR100/methamphetamine FR10) were reinstituted after a given FR manipulation and until choice behavior was stable.

\section{Drugs}

(+)-Methamphetamine $\mathrm{HCl}$ was provided by the National Institute on Drug Abuse (Bethesda, MD) Drug Supply Program. Bupropion $\mathrm{HCl}$ was synthesized by BE Blough (RTI International, Research Triangle Park, NC). Methamphetamine and bupropion doses are expressed as the salt forms listed above. Risperidone (Sigma Chemical, St Louis, MO) was dissolved in $2 \%$ lactic acid (85\% w/w; Sigma Chemical) and sodium hydroxide was added to reach a $\mathrm{pH}$ of approximately 5-6. All drug solutions were passed through a sterile $0.2-\mu \mathrm{m}$ filter (EMD Millipore, Billerica, MA) before IV administration.

\section{Data Analysis}

The primary dependent measures for the choice session were (1) percentage of methamphetamine choice, defined as (the number of ratios completed on the methamphetamineassociated key/total number of ratios completed) $\times 100$ and (2) the number of ratio requirements (hereafter referred to as 'choices') completed. The mean of the last 3 days of each experimental condition for each monkey for each of these measures were then plotted as a function of unit methamphetamine dose or the corresponding response period during the behavioral session. Results were analyzed using mixedmodel analysis with unit methamphetamine dose, experimental manipulation (treatment drug dose, extinction condition, or FR manipulation) as the fixed main effects and subjects as the random effect. Additional dependent measures collected were total choices, food choices, and methamphetamine choices for the entire behavioral session. The mean of the last 3 days of each experimental condition for each monkey for each of these measures were then plotted as a function of each dependent measure. Results were analyzed using two-way repeated-measures analysis of variance with experimental manipulation and dependent measure as the main factor. Post-hoc comparisons against baseline '+ Saline' conditions within a given methamphetamine dose were performed using the Dunnett's test following 
a significant main effect of experimental manipulation or methamphetamine dose $\times$ experimental manipulation interaction as appropriate. The criterion for significance was set a priori at the $95 \%$ confidence level $(p<0.05)$. All analyses were conducted using JMP Pro 11.1.1 for Mac (SAS, Cary, NC).

\section{RESULTS}

\section{Baseline Methamphetamine vs Food Choice}

Figure 1a shows the stability of baseline methamphetamine $v s$ food choice for the entire study duration and when saline was continuously infused through the 'treatment' lumen of the double-lumen catheter. There was an average of $9.3 \pm 3.9$ months (range: 6-16) between the first and last baseline methamphetamine $v s$ food choice dose-effect functions. Food was preferred over no or small (0.01 and $0.032 \mathrm{mg} / \mathrm{kg} /$ injection) methamphetamine doses. $0.1 \mathrm{mg} / \mathrm{kg} /$ injection methamphetamine maintained at least $50 \%$ preference and the largest unit methamphetamine dose $(0.32 \mathrm{mg} / \mathrm{kg} /$ injection $)$ maintained exclusive preference. Figure $1 \mathrm{~b}$ shows the number of choices completed per session component and choices decreased as a function of increasing unit methamphetamine doses, and there were no differences between the different experimental manipulations. Figure 1c shows total choices, food choices, and methamphetamine choices completed during each session, and there were no differences between the different experimental manipulations.

\section{Effects of Bupropion and Risperidone Treatment on Methamphetamine Choice}

Figure 2a shows that 7-day continuous treatment failed to significantly alter methamphetamine $v s$ food choice at any bupropion dose. Figure 2c shows that 7-day continuous $1.8 \mathrm{mg} / \mathrm{kg} / \mathrm{h}$ bupropion treatment significantly decreased both total and food choices completed during the entire choice session (bupropion dose: $\mathrm{F}_{3,9}=4.3, p=0.0385$ ). Supplementary Figure S1 shows days 1-3 of each bupropion treatment, and these results were generally consistent with days 5-7. Supplementary Table S1 shows that bupropion treatments did not significantly alter the methamphetamine $v s$ food choice $\mathrm{ED}_{50}$ value. Figure $2 \mathrm{~b}$ shows that 7 -day continuous $0.0056 \mathrm{mg} / \mathrm{kg} / \mathrm{h}$ risperidone treatment increased methamphetamine $v s$ food choice and produced a leftward shift in the methamphetamine choice dose-effect function compared with baseline conditions when saline was infused through the 'treatment' lumen (interaction: $\mathrm{F}_{12,35.9}=3.3, p=0.0026$ ). Figure $2 \mathrm{~d}$ shows that 7-day continuous $0.0056 \mathrm{mg} / \mathrm{kg} / \mathrm{h}$ risperidone treatment significantly decreased food choices and increased methamphetamine choices completed during the entire choice session (interaction: $\mathrm{F}_{6,12}=15.0, p<0.0001$ ). Supplementary Figure S2 shows days 1-3 of each risperidone treatment, and results were generally consistent with days 5-7. Supplementary Table S1 shows that risperidone treatments did not significantly alter the methamphetamine $v s$ food choice $\mathrm{ED}_{50}$ value.
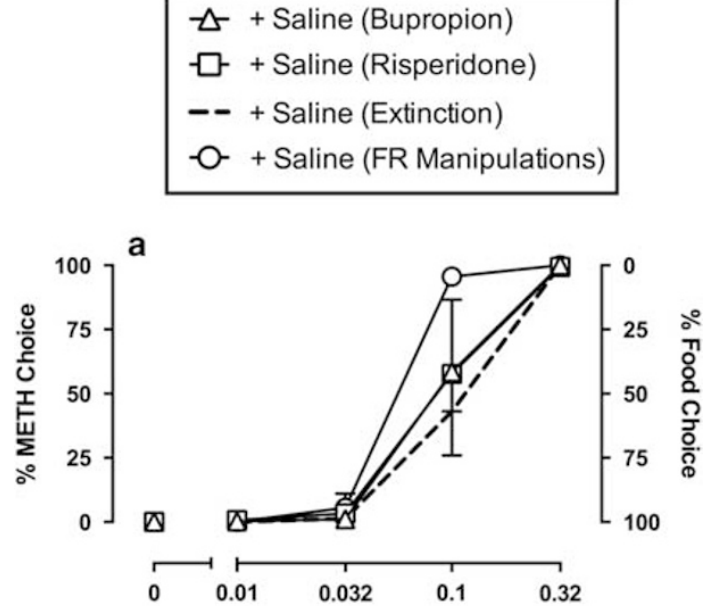

b
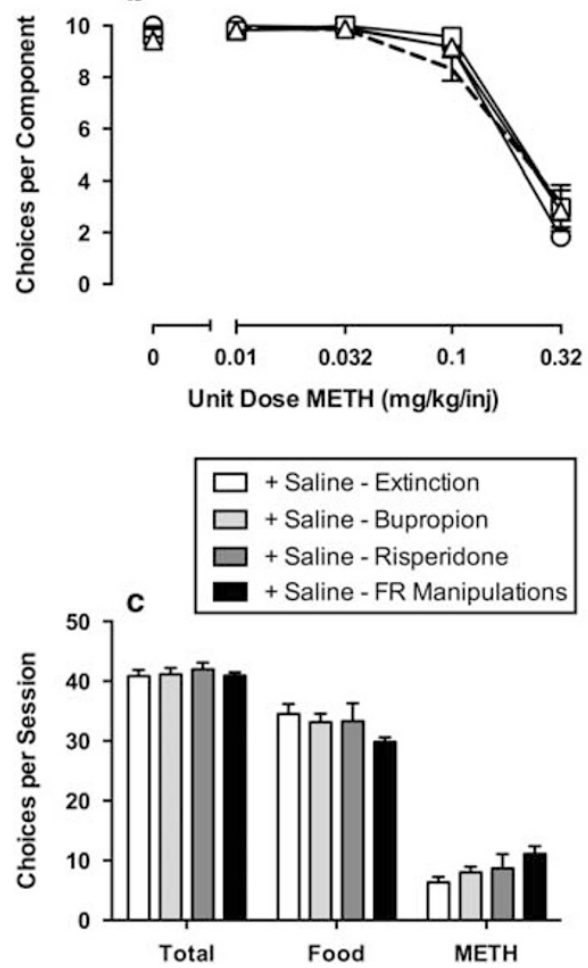

Figure I Comparison of baseline methamphetamine vs food choice during continuous saline treatment over the entire experimental testing period in rhesus monkeys $(n=3-6)$. ( $a$ and b) Abscissa: unit dose methamphetamine in $\mathrm{mg} / \mathrm{kg} /$ injection (log scale). (a) Left ordinate: percentage of methamphetamine choice. Right ordinate: percentage of food choice. (b) Ordinate: choices completed per component. (c) Ordinate: number of choices per session. Abscissa: experimental end point. Panel shows summary data for total choices, food choices, and methamphetamine choices summed across all methamphetamine doses. All points and bars represent mean \pm SEM obtained during the 3 days preceding each 7-day experimental period while saline was infused through the 'treatment' lumen of the double-lumen catheter.

\section{Effects of Environmental Manipulations on Methamphetamine Choice}

Figure 3a shows that 7 days of removing methamphetamine availability significantly decreased choice of methamphetamine-associated stimuli, whereas 7 days of removing food 

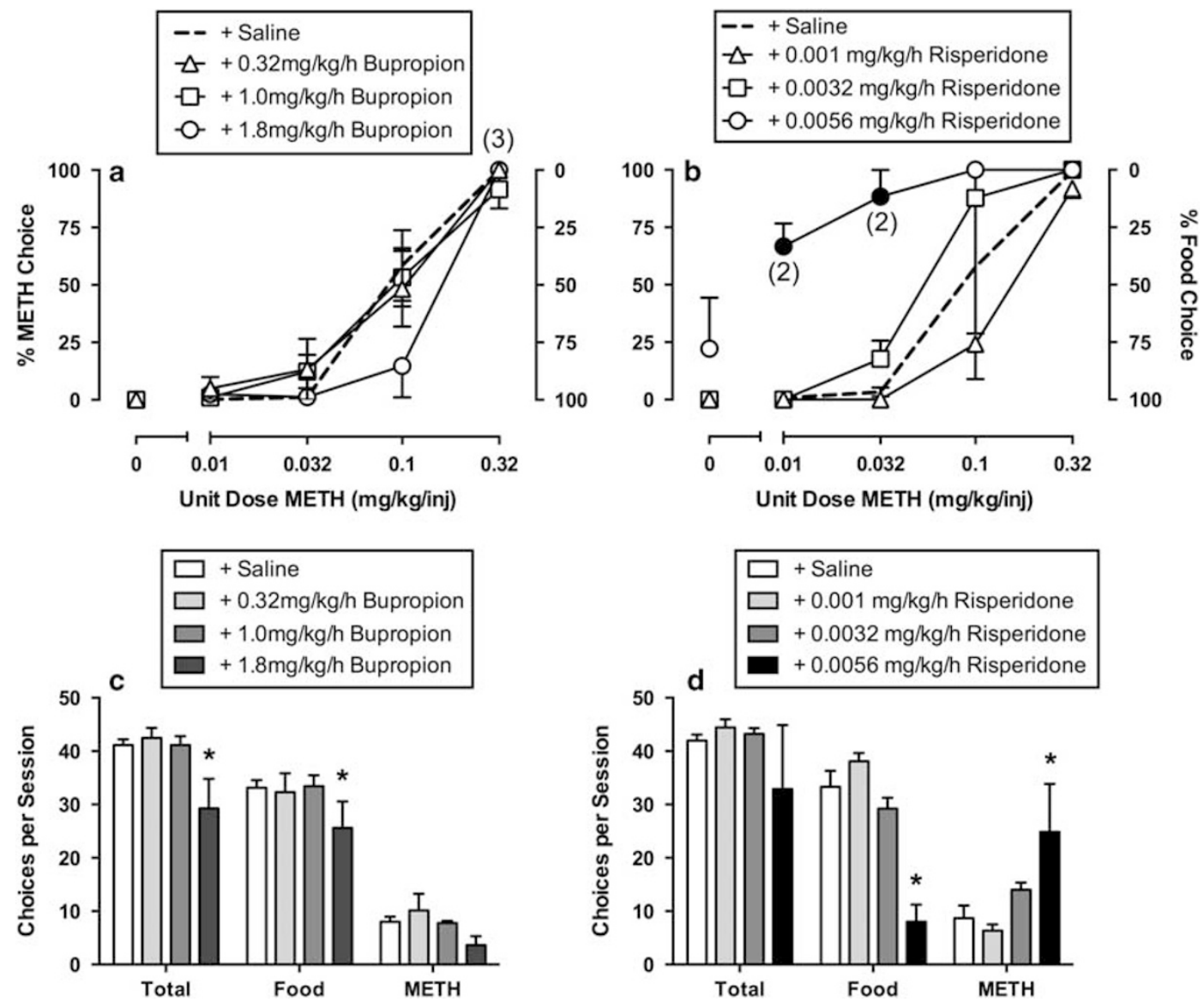

Figure 2 Effects of continuous 7-day bupropion $(0.32-1.8 \mathrm{mg} / \mathrm{kg} / \mathrm{h} ; \mathrm{n}=4)$ and risperidone $(0.00 \mathrm{I}-0.0056 \mathrm{mg} / \mathrm{kg} / \mathrm{h} ; n=3)$ treatment on choice between methamphetamine and food in rhesus monkeys. Panels a and $\mathrm{c}$ show bupropion effects, and panels $\mathrm{b}$ and $\mathrm{d}$ show risperidone effects. All points and bars represent mean \pm SEM obtained during days 5-7 of each 7-day treatment period. Filled symbols indicate significantly different $(p<0.05)$ from baseline (+ saline) within a methamphetamine dose. Asterisk (*) indicates significantly different from baseline (+ saline) conditions. Numbers in parentheses indicate the number of subjects contributing to that data point if fewer than the total number of subjects tested (bupropion, $n=4$; risperidone, $n=3$ ). This number indicates treatment eliminated responding in one or more monkeys during that component of the choice procedure. Otherwise, figure details are the same as in Figure I above.

availability significantly increased methamphetamine choice (interaction: $\mathrm{F}_{8,56}=2.8, p=0.0117$ ), producing a leftward shift in the methamphetamine choice dose-effect function. Figure $3 \mathrm{c}$ shows that removing food availability significantly decreased both total choices and 'food' choices and increased methamphetamine choices during the choice session; removing methamphetamine availability significantly increased the number of food choices earned (interaction: $\mathrm{F}_{4,16}=20.8, p<0.0001$ ). Supplementary Figure $\mathrm{S} 3$ shows days 1-3 of each extinction experiment, and results suggest that behavior continued to extinguish on the non-reinforced key as a function of time. Figure $3 \mathrm{~b}$ shows that methamphetamine $v s$ food choice was not significantly altered when the FR requirement on the food- and methamphetamineassociated keys were either 100 or 10. Furthermore, increasing the methamphetamine FR requirement to 100 or decreasing the food FR requirement to 10 did not significantly alter the number of total, food, or methamphetamine choices completed (Figure 3d). Analysis of experimental days 1-3 for each of the FR manipulations also did not demonstrate any significant effects on methamphetamine choice.

\section{DISCUSSION}

There were two major aims of the present study. The first aim was to establish experimental conditions that would permit assessment of behavioral allocation between food and multiple IV methamphetamine doses within a single experimental session. The second aim was to determine the sensitivity of the model to both pharmacological and environmental manipulations. Overall, there were three main findings. First, we established a within-session dose-effect function of methamphetamine $v s$ food choice, and IV methamphetamine maintained a dose-dependent preference over a non-drug alternative food reinforcer. Second, bupropion treatment failed to significantly alter methamphetamine $v s$ food choice and these results were generally consistent with previous double-blind placebo-controlled clinical trials. In contrast, risperidone treatment enhanced methamphetamine $v s$ food choice, and these results were also generally consistent with previous human laboratory and clinical trials. Finally, removing food or methamphetamine availability produced the predicted shift in behavioral allocation toward the only reinforced key. Under conditions where the FR 

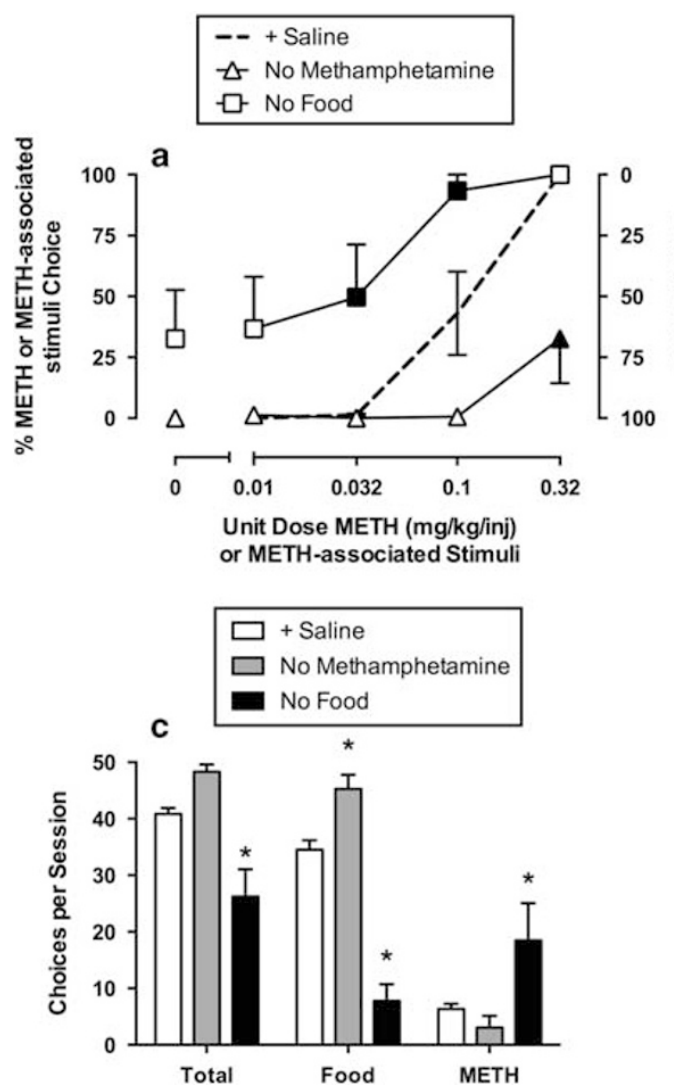
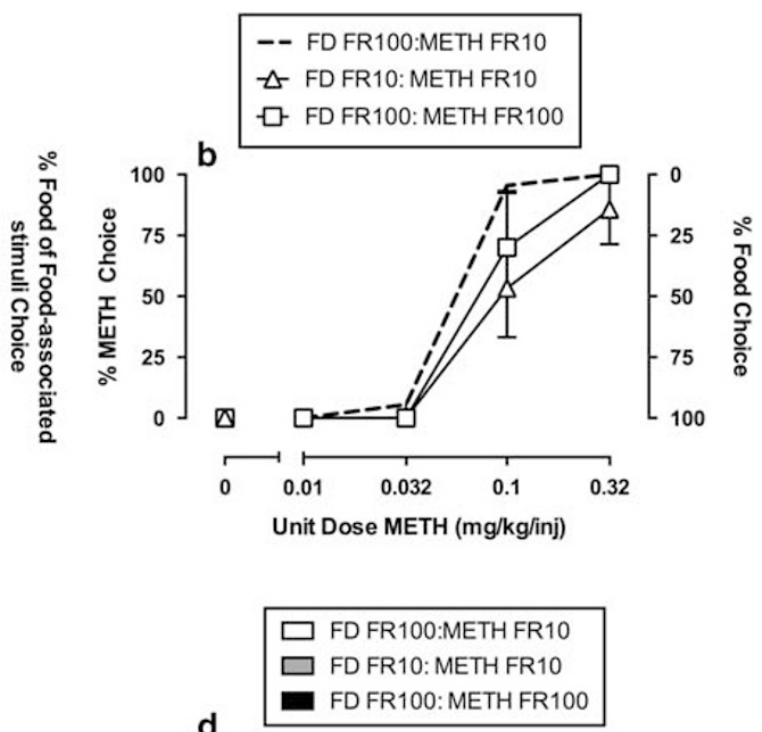

d

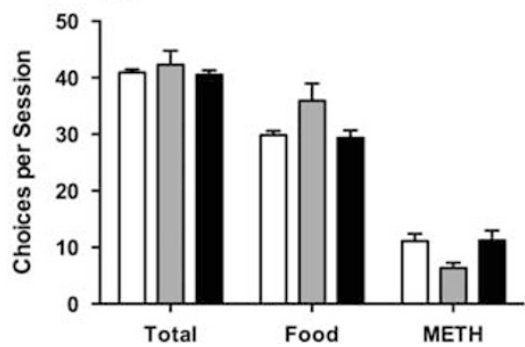

Figure 3 Effects of removing methamphetamine or food availability for 7 consecutive days $(n=5)$ or manipulating the fixed-ratio (FR) requirement on the food- or methamphetamine-associated key $(n=3)$ on behavioral allocation in rhesus monkeys. Panels a and c show effects of removing reinforcer availability, and panels $b$ and $d$ show effects of FR manipulations. (a and b) Abscissae: unit dose methamphetamine in mg/kg/injection (log scale) during + saline and 'no food' conditions or unit dose methamphetamine associated with prevailing discriminative stimuli during the 'no methamphetamine' condition. (a and b) Left ordinate: percentage of methamphetamine choice or methamphetamine-associated stimuli. (a and b) Right ordinate: percentage of food choice or foodassociated stimuli. Otherwise, figure details are the same as in Figure I above.

requirements on the food- and methamphetamine-associated keys were similar, methamphetamine choice was not significantly altered compared with baseline conditions where the FR requirement on the food-associated key was 10 times higher than the FR requirement on the methamphetamineassociated key. Consequently, the negative results with bupropion and risperidone in the present study are concordant with negative results in human laboratory studies and double-blind, placebo-controlled trials and support the potential validity of preclinical methamphetamine $v s$ food choice procedures as models of methamphetamine addiction. Overall, these results may have implications for both the mechanisms and treatment of methamphetamine addiction.

\section{Baseline Methamphetamine Choice and Effects of Environmental Manipulations}

Consistent with another study using nonhuman primates (John et al, 2015a) but not rodents (Ping and Kruzich, 2008), methamphetamine maintained a dose-dependent increase in preference over food. Interestingly, the unit methamphetamine dose necessary to maintain consistent and exclusive methamphetamine preference was a half-log larger than those required to maintain cocaine (Negus, 2003) or heroin (Negus, 2006) under similar procedural conditions. Similar potency differences in maintaining near exclusive preference between cocaine and methamphetamine choice were also reported by John et al, (2015a). In contrast to these choice studies, methamphetamine maintains similar patterns of drug selfadministration at smaller unit drug doses compared with cocaine under both FR and progressive-ratio schedules of reinforcement (Fantegrossi et al, 2002; Lile et al, 2013). Overall, these results suggest that simply introducing a concurrent schedule of drug and food availability produced larger potency shifts in the relative reinforcing strength of methamphetamine compared with cocaine.

Effects of reinforcer magnitude manipulations on methamphetamine $v s$ food choice were also determined by eliminating methamphetamine or food presentation while retaining presentation of the methamphetamine- or food-associated discriminative stimuli. As hypothesized, elimination of methamphetamine delivery decreased methamphetamine-associated choice and produced a reciprocal increase in food choice. Elimination of food delivery produced a leftward shift in the methamphetamine choice dose-effect function and an approximate 10-fold increase in the potency of methamphetamine to maintain responding on 
the methamphetamine-associated key. Overall, the present results demonstrate the sensitivity of the procedure to reinforcer magnitude manipulations. Moreover, these reinforcer magnitude manipulations provide an empirical framework for interpreting bupropion and risperidone treatment effects.

Previous human laboratory (Stoops et al, 2012) and preclinical studies (Nader and Woolverton, 1992; Negus, 2003) have demonstrated cocaine $v s$ alternative reinforcer choice to be sensitive to response requirement manipulations. Recently, methamphetamine vs money choice in humans was also reported to be sensitive to response requirement manipulations such that a sixfold larger response requirement for money slightly, but not significantly, increased the number of methamphetamine capsules earned (Bennett et al, 2013). In the present study, a 10-fold larger response requirement for food pellets $v s$ methamphetamine injections also produced a slight, nonsignificant, increase in methamphetamine preference, similar to the study by Bennett (2013). Moreover, the small, nonsignificant shifts in methamphetamine choice in the present study when the response requirement for both reinforcers was an FR100 are in contrast to previous results with cocaine. Under similar choice procedures, cocaine $v s$ food choice was significantly attenuated with the FR response requirement matched at either FR100 or FR10 (Banks et al, 2013; Negus, 2003). Overall, the results of the present study are consistent with the results from a human laboratory methamphetamine choice study and suggest that methamphetamine choice may be less sensitive to response requirement 'cost' manipulations than cocaine choice.

\section{Effects of Bupropion and Risperidone on Methamphetamine Choice}

In the present study, methamphetamine $v s$ food choice was evaluated during continuous treatment with the monoamine uptake inhibitor bupropion that attempted to model bupropion treatment conditions in human laboratory and clinical trials. The present results were consistent with previous clinical trials demonstrating weak or no bupropion treatment efficacy for methamphetamine addiction (Elkashef et al, 2008; Heinzerling et al, 2014; Shoptaw et al, 2008) and a recent human laboratory study demonstrating no bupropion treatment efficacy on methamphetamine choice (Stoops et al, 2015). The present results were also somewhat consistent with previous findings examining acute bupropion pretreatments on methamphetamine self-administration in rhesus monkeys (Schindler et al, 2011). Acute bupropion pretreatment significantly decreased rates of methamphetaminemaintained responding at some methamphetamine doses but did not significantly alter methamphetamine intake (Schindler et al, 2011). In rat methamphetamine selfadministration studies, both acute and repeated bupropion pretreatment decreased methamphetamine-maintained responding (Reichel et al, 2008; Reichel et al, 2009). However, tolerance developed to these bupropion effects during repeated administration (Reichel et al, 2009). Overall, this body of scientific literature does not support bupropion treatment efficacy for methamphetamine addiction.

In contrast to bupropion treatment effects, treatment with the non-selective DA antagonist risperidone produced a leftward shift in the methamphetamine $v s$ food dose-effect function. These risperidone effects on methamphetamine choice were functionally similar to effects of removing food availability during the behavioral choice session, although albeit by distinct mechanisms. Previous open-label (Meredith et al, 2009) and randomized, double-blind (Nejtek et al, 2008) trials have suggested weak risperidone treatment efficacy for methamphetamine addiction. However, two points are worth noting regarding these clinical trials. First, retention rates for these two studies were generally poor with $16 \%$ (Nejtek et al, 2008) and 35\% (Meredith et al, 2009) completion. Second, no double-blind, placebo-controlled clinical trials have been initiated based on these open-label trial results. Furthermore, in a recent meta-analysis of clinical trials examining antipsychotic treatment efficacy for cocaine- or amphetamine-type addictions, the authors concluded that antipsychotic compounds had no significant treatment efficacy but did have significantly more adverse effects compared with placebo (Kishi et al, 2013).

The present risperidone results are consistent with doubleblind, placebo-controlled trials examining treatment efficacy with the DA partial agonist aripiprazole. Aripiprazole treatment produced no significant effect in two doubleblind, placebo-controlled clinical trials for methamphetamine addiction (Coffin et al, 2013; Sulaiman et al, 2013) and resulted in significantly more amphetamine-positive urines compared with placebo in another clinical trial (Tiihonen et al, 2007). Moreover, these risperidone treatment effects were similar to buspirone and selective DA D3 receptor antagonist effects on methamphetamine $v s$ food choice in monkeys (John et al, 2015a, b). However, the present results are somewhat inconsistent with previous preclinical studies examining DA antagonist or DA partial agonist effects. For example, DA D1-selective (Brennan et al, 2009) and D3selective (Higley et al, 2011a; Higley et al, 2011b; Orio et al, 2010) antagonists and the DA partial agonist aripiprazole (Wee et al, 2007) decreased methamphetamine selfadministration. Acute aripiprazole pretreatment attenuated methamphetamine self-administration of small but not larger unit methamphetamine doses in humans (Stoops et al, 2013). Overall, this body of literature suggests preclinical methamphetamine choice procedures produce more concordant results with human laboratory and clinical trials.

\section{Implications for Methamphetamine Addiction Medication Development Research}

In summary, the results of the present study, in agreement with other preclinical methamphetamine choice studies, support the utility of preclinical methamphetamine choice procedures to interrogate both the mechanisms of and treatment strategies for methamphetamine addiction. However, without a pharmacological compound that has demonstrated treatment efficacy to reduce methamphetamine use in a double-blind placebo-controlled clinical trial, preclinical methamphetamine choice procedures are only able to demonstrate concordant results. To demonstrate predictive validity in a preclinical model, both positive and negative results should be reported. Thus more methamphetamine medication development research is clearly warranted to identify a pharmacotherapeutic strategy that successfully decreases methamphetamine use. 


\section{FUNDING AND DISCLOSURE}

Research reported in this publication was supported by the National Institute on Drug Abuse of the National Institutes of Health under Award Numbers R01DA031718 and R01DA012970. The content is solely the responsibility of the authors and does not necessarily represent the official views of the National Institutes of Health. Dr Banks declares NIH has funded his research. During the past 3 years, he has received compensation as a collaborator with Purdue pharmaceutical for projects related to opioid pharmacology and drug development. Dr Banks declares that the present study was not related to this professional relationship and should not be perceived as constituting a conflict of interest. Dr. Blough declares NIH has funded his research.

\section{ACKNOWLEDGMENTS}

We appreciate the technical assistance of Jennifer Gough, Crystal Reyns, and Doug Smith. We acknowledge Kevin Costa for writing the original program version. We are grateful for comments from Steve Negus on an earlier version of this manuscript.

\section{REFERENCES}

Banks ML, Blough BE, Stevens Negus S (2013). Interaction between behavioral and pharmacological treatment strategies to decrease cocaine choice in rhesus monkeys. Neuropsychopharmacology 38: 395-404.

Banks ML, Negus SS (2012). Preclinical determinants of drug choice under concurrent schedules of drug self-administration. $A d v$ Pharmacol Sci 2012: 281768.

Bennett JA, Stoops WW, Rush CR (2013). Alternative reinforcer response cost impacts methamphetamine choice in humans. Pharmacol Biochem Behav 103: 481-486.

Brennan KA, Carati C, Lea RA, Fitzmaurice PS, Schenk S (2009). Effect of D1-like and D2-like receptor antagonists on methamphetamine and 3,4-methylenedioxymethamphetamine selfadministration in rats. Behav Pharmacol 20: 688-694.

Caprioli D, Zeric T, Thorndike EB, Venniro M (2015). Persistent palatable food preference in rats with a history of limited and extended access to methamphetamine self-administration. Addict Biol (doi:10.1111/adb.12220).

Coffin PO, Santos G-M, Das M, Santos DM, Huffaker S, Matheson T et al (2013). Aripiprazole for the treatment of methamphetamine dependence: a randomized, double-blind, placebo-controlled trial. Addiction 108: 751-761.

Comer SD, Ashworth JB, Foltin RW, Johanson CE, Zacny JP, Walsh SL (2008). The role of human drug self-administration procedures in the development of medications. Drug Alcohol Depend 96: 1-15.

Courtney KE, Ray LA (2014). Methamphetamine: an update on epidemiology, pharmacology, clinical phenomenology, and treatment literature. Drug Alcohol Depend 143: 11-21.

De La Garza R, Zorick T, London ED, Newton TF (2010). Evaluation of modafinil effects on cardiovascular, subjective, and reinforcing effects of methamphetamine in methamphetamine-dependent volunteers. Drug Alcohol Depend 106: 173-180.

Elkashef AM, Rawson RA, Anderson AL, Li S-H, Holmes T, Smith EV et al (2008). Bupropion for the treatment of methamphetamine dependence. Neuropsychopharmacology 33: 1162-1170.

Fantegrossi WE, Ullrich T, Rice KC, Woods JH, Winger G (2002). 3,4-Methylenedioxymethamphetamine (MDMA, 'ecstasy') and its stereoisomers as reinforcers in rhesus monkeys: serotonergic involvement. Psychopharmacology 161: 356.
Goodwin JS, Larson GA, Swant J, Sen N, Javitch JA, Zahniser NR et al (2009). Amphetamine and methamphetamine differentially affect dopamine transporters in vitro and in vivo. J Biol Chem 284: $2978-2989$.

Griffiths RR, Wurster RM, Brady JV (1975). Discrete-trial choice procedure: effects of naloxone and methadone on choice between food and heroin. Pharmacol Rev 27: 357-365.

Haney M, Spealman R (2008). Controversies in translational research: drug self-administration. Psychopharmacology 199: 403-419.

Hart CL, Ward AS, Haney M, Foltin RW, Fischman MW (2001). Methamphetamine self-administration by humans. Psychopharmacology 157: 75.

Heinzerling KG, Swanson A-N, Hall TM, Yi Y, Wu Y, Shoptaw SJ (2014). Randomized, placebo-controlled trial of bupropion in methamphetamine-dependent participants with less than daily methamphetamine use. Addiction 109: 1878-1886.

Heyman GH (2009). Addiction: A Disorder of Choice. Harvard University Press: Cambridge, MA, USA.

Higley AE, Kiefer SW, Li X, Gaál J, Xi Z-X, Gardner EL (2011a). Dopamine D3 receptor antagonist SB-277011A inhibits methamphetamine self-administration and methamphetamine-induced reinstatement of drug-seeking in rats. Eur J Pharmacol 659: 187-192.

Higley AE, Spiller K, Grundt P, Newman AH, Kiefer SW, Xi Z-X et al (2011b). PG01037, a novel dopamine D3 receptor antagonist, inhibits the effects of methamphetamine in rats. J Psychopharmacol 25: 263-273.

John WS, Banala A, Newman A, Nader M (2015a). Effects of buspirone and the dopamine D3 receptor compound PG619 on cocaine and methamphetamine self-administration in rhesus monkeys using a food-drug choice paradigm. Psychopharmacology 232: 1279-1289.

John WS, Newman AH, Nader MA (2015b). Differential effects of the dopamine D3 receptor antagonist PG01037 on cocaine and methamphetamine self-administration in rhesus monkeys. Neuropharmacology 92: 34-43.

Kirkpatrick MG, Gunderson EW, Johanson C-E, Levin FR, Foltin RW, Hart CL (2012). Comparison of intranasal methamphetamine and D-amphetamine self-administration by humans. Addiction 107: 783-791.

Kishi T, Matsuda Y, Iwata N, Correll CU (2013). Antipsychotics for cocaine or psychostimulant dependence: systematic review and meta-analysis of randomized, placebo-controlled trials. J Clin Psychiatry 74: e1169-e1180.

Lako IM, van den Heuvel ER, Knegtering H, Bruggeman R, Taxis K (2013). Estimating dopamine $\mathrm{D}(2)$ receptor occupancy for doses of 8 antipsychotics: a meta-analysis. J Clin Psychopharmacol 33: $675-681$.

Lile JA, Charnigo RJ, Nader MA (2013). The relative reinforcing strength of methamphetamine and D-amphetamine in monkeys self-administering cocaine. Behav Pharmacol 24: 482-485.

Meredith CW, Jaffe C, Cherrier M, Robinson JP, Malte CA, Yanasak EV et al (2009). Open trial of injectable risperidone for methamphetamine dependence. J Addict Med 3: 55-65.

Nader MA, Woolverton WL (1992). Effects of increasing response requirement on choice between cocaine and food in rhesus monkeys. Psychopharmacology 108: 295-300.

Negus SS (2003). Rapid assessment of choice between cocaine and food in rhesus monkeys: effects of environmental manipulations and treatment with D-amphetamine and flupenthixol. Neuropsychopharmacology 28: 919-931.

Negus SS (2006). Choice between heroin and food in nondependent and heroin-dependent rhesus monkeys: effects of naloxone, buprenorphine, and methadone. J Pharmacol Exp Ther 317: 711-723.

Nejtek VA, Avila M, Chen LA, Zielinski T, Djokovic M, Podawiltz A et al (2008). Do atypical antipsychotics effectively treat co-occurring bipolar disorder and stimulant dependence? A randomized, double-blind trial. J Clin Psychiatry 69: 1257-1266. 
Newton TF, Roache JD, De La Garza R II, Fong T, Wallace CL, Li S-H et al (2006). Bupropion reduces methamphetamineinduced subjective effects and cue-induced craving. Neuropsychopharmacology 31: 1537-1544.

Orio L, Wee S, Newman AH, Pulvirenti L, Koob GF (2010). The dopamine D3 receptor partial agonist CJB090 and antagonist PG01037 decrease progressive ratio responding for methamphetamine in rats with extended-access. Addiction Biol 15: 312-323.

Ping A, Kruzich PJ (2008). Concurrent access to sucrose pellets decreases methamphetamine-seeking behavior in Lewis rats. Pharmacol Biochem Behav 90: 492-496.

Reichel CM, Linkugel JD, Bevins RA (2008). Bupropion differentially impacts acquisition of methamphetamine selfadministration and sucrose-maintained behavior. Pharmacol Biochem Behav 89: 463-472.

Reichel CM, Murray JE, Grant KM, Bevins RA (2009). Bupropion attenuates methamphetamine self-administration in adult male rats. Drug Alcohol Depend 100: 54-62.

SAMHSA (2014). Results from the 2013 National Survey on Drug Use and Health: Summary of National Findings. In: SAMHSA: Rockville, MD, USA.

Schindler CW, Gilman JP, Panlilio LV, McCann DJ, Goldberg SR (2011). Comparison of the effects of methamphetamine, bupropion, and methylphenidate on the self-administration of methamphetamine by rhesus monkeys. Exp Clin Psychopharmacol 19: 1-10.

Shoptaw S, Heinzerling KG, Rotheram-Fuller E, Steward T, Wang J, Swanson A-N et al (2008). Randomized, placebo-controlled trial of bupropion for the treatment of methamphetamine dependence. Drug Alcohol Depend 96: 222-232.

Simmler LD, Wandeler R, Liechti ME (2013). Bupropion, methylphenidate, and 3,4-methylenedioxypyrovalerone antagonize methamphetamine-induced efflux of dopamine according to their potencies as dopamine uptake inhibitors: implications for the treatment of methamphetamine dependence. BMC Res Notes 6: 1-5.

Stoops WW, Bennett JA, Lile JA, Sevak RJ, Rush CR (2013). Influence of aripiprazole pretreatment on the reinforcing effects of methamphetamine in humans. Prog Neuropsychopharmacol Biol Psychiatry 47: 111-117.

Stoops WW, Lile JA, Glaser PEA, Hays LR, Rush CR (2012). Alternative reinforcer response cost impacts cocaine choice in humans. Prog Neuropsychopharmacol Biol Psychiatry 36: 189-193.

Stoops WW, Pike E, Hays LR, Glaser PE, Rush CR (2015). Naltrexone and bupropion, alone or combined, do not alter the reinforcing effects of intranasal methamphetamine. Pharmacol Biochem Behav 129: 45-50.

Sulaiman AH, Gill JS, Said MA, Zainal NZ, Hussein HM, Guan NC (2013). A randomized, placebo-controlled trial of aripiprazole for the treatment of methamphetamine dependence and associated psychosis. Int J Psychiatry Clin Pract 17: 131-138.

Tiihonen J, Kuoppasalmi K, Fohr J, Tuomola P, Kuikanmaki O, Vorma $\mathrm{H}$ et al (2007). A comparison of aripiprazole, methylphenidate, and placebo for amphetamine dependence. Am J Psychiatry 164: 160-162.

UNODC (2013). World Drug Report 2013. In: UNODC: Vienna, Austria.

Vocci FJ (2007). Can replacement therapy work in the treatment of cocaine dependence? And what are we replacing anyway? Addiction 102: 1888-1889.

Wachtel SR, Ortengren A, Wit Hd (2002). The effects of acute haloperidol or risperidone on subjective responses to methamphetamine in healthy volunteers. Drug Alcohol Depend 68: 23-33.

Wee S, Wang Z, Woolverton WL, Pulvirenti L, Koob GF (2007). Effect of aripiprazole, a partial dopamine D2 receptor agonist, on increased rate of methamphetamine self-administration in rats with prolonged session duration. Neuropsychopharmacology 32: 2238-2247.

Woolverton WL, Balster RL (1981). Effects of antipsychotic compounds in rhesus monkeys given a choice between cocaine and food. Drug Alcohol Depend 8: 69-78.

Wurster RM, Griffiths RR, Findley JD, Brady JV (1977). Reduction of heroin self-administration in baboons by manipulation of behavioral and pharmacological conditions. Pharmacol Biochem Behav 7: 519-528.

Supplementary Information accompanies the paper on the Neuropsychopharmacology website (http://www.nature.com/npp) 